\title{
Acessibilidade e permanência: um estudo do programa institucional de apoio aos estudantes da Universidade Federal de Santa Catarina ${ }^{1}$
}

\author{
Ana Paula de Oliveira Santana ${ }^{2}$ \\ Lais Oliva Donida ${ }^{3}$ \\ Ana Lucia Lima da Costa Pimenta Monteiro ${ }^{4}$ \\ Suelen Machado Silva ${ }^{5}$
}

\section{Introdução}

Nos últimos anos temos efetivamente presenciado mudanças consideráveis nas políticas educacionais brasileiras, principalmente após o Brasil tornar-se signatário da Declaração de Salamanca, resultante da Conferência Mundial sobre

1 Pesquisa vinculada ao projeto em rede "Acessibilidade no Ensino Superior", da Faculdade de Filosofia e Ciências da Universidade Estadual Paulista (FFC-Unesp), Marília/ SP, financiada pelo Programa Observatório da Educação (Obeduc), da Coordenação de Aperfeiçoamento de Pessoal de Nível Superior (Capes) - Edital n. 49/2012.

2 UFSC - Universidade Federal de Santa Catarina. Departamento de Fonoaudiologia Programa de Pós-Graduação em Linguística. Florianópolis - Santa Catarina - Brasil. Coordenadora do Núcleo de Apoio à Pesquisa da UFSC no projeto em rede "Acessibilidade no Ensino Superior" (Obeduc/Capes). Agradeço também pelo apoio a esta pesquisa ao CNPq (Bolsista produtividade). anaposantana@hotmail.com

3 UFSC - Universidade Federal de Santa Catarina. Departamento de Fonoaudiologia. Florianópolis - Santa Catarina - Brasil. Graduanda. Bolsista de Iniciação Científica Obeduc/Capes. lais.donida@gmail.com

4 UFSC - Universidade Federal de Santa Catarina. Departamento de Fonoaudiologia Programa de Pós-Graduação em Linguística. Florianópolis - Santa Catarina - Brasil. Mestranda. Bolsista Obeduc/Capes. anamonteiro1970@hotmail.com

5 UFSC - Universidade Federal de Santa Catarina. Departamento de Fonoaudiologia. Florianópolis - Santa Catarina - Brasil. Graduanda. Bolsista de Iniciação Científica Obeduc/Capes. suelenmachadosilva@hotmail.com 
Necessidades Educativas Especiais de 1994. A partir dela, vários movimentos sociais e políticos implicaram leis e decretos importantes para a educação especial: as Leis de Diretrizes e Bases da Educação (BRASIL, 1996); Decreto n. 5.626, de 22 de dezembro de 2005 (BRASIL, 2005); a Convenção sobre os Direitos das Pessoas com Deficiência (ONU, 2006); a Política Nacional de Educação Especial na Perspectiva da Educação Inclusiva (BRASIL, 2008b), dentre outros.

Ressalta-se ainda que a Política Nacional de Educação Especial na Perspectiva da Educação Inclusiva (BRASIL, 2008) define como público-alvo da educação especial alunos com deficiências, transtornos globais de desenvolvimento e altas habilidades/superdotação. Tal diretriz já estava descrita na Lei de Diretrizes e Bases da Educação Nacional (BRASIL, 1996), passando a ser educação especial a modalidade de ensino que perpassa todos os níveis de educação escolar - educaçáo infantil, ensino fundamental e médio e ensino superior. Ainda, perpassa a educação de jovens e adultos, a educação indígena e a educação do campo. $\mathrm{O}$ objetivo central é a inclusão dos alunos com necessidades educativas especiais no ensino regular.

O Censo do Ensino Superior de 2009 indica a matrícula de 20.019 alunos com deficiência. Contudo, este número ainda é pequeno devido ao tamanho dessa populaçáo (BRASIL, 2010b). No Censo Escolar de 2012, o Instituto Nacional de Estudos e Pesquisas Educacionais "Anísio Teixeira" (Inep) informou que 27.143 alunos com necessidades educativas especiais estavam matriculados no ensino superior, em um universo de 9.532.085 alunos (BRASIL, 2014a).

Vemos assim o ingresso de um número cada vez maior desses alunos na universidade, o que faz com que haja mudanças nas políticas educacionais brasileiras. De acordo com Masini e Bazon (2005), somente a partir de 1998 as universidades passaram a discutir a inclusão educacional dos estudantes, devido às políticas públicas que foram surgindo, o que antes era tema apenas na educação infantil e ensino fundamental. A partir daí foi necessário criar estratégias não só para o acesso, assim como para a permanência dos alunos dentro da educação superior (VARGAS, 2006).

Para Saravali (2005), a democratização do ensino envolve não somente a garantia do acesso à universidade, mas também a permanência. Neste sentido, quando se fala sobre inclusão, fala-se não só da democratização do ensino. Incluir, nesse caso, seria todo o percurso do aluno desde o acesso ao site da instituiçáo de ensino para a inscrição no vestibular, até sua chegada e permanência no ambiente educacional.

Scardua (2008) acrescenta que a inclusão visa dar a garantia tanto de acesso como de permanência do aluno na instituição, promovendo o desenvolvimento e a expansão de vagas para o público da educação especial. Dentro da instituição, o aluno que não consegue acompanhar o ritmo da turma, por náo aprender no mesmo tempo e da mesma forma que os demais, é vítima de preconceito. De modo geral, parte-se de uma concepção de homogeneidade, como se houvesse apenas uma forma de ensinar e uma única forma de aprender, exigindo que todos aprendam no mesmo período de tempo. 
Assim, é necessária uma universidade mais aberta para as diferenças, que explore diferentes estratégias de ensino, e que saiba aproveitar a potencialidade de cada aluno, explorando aquilo que ele tem de melhor, sem preconceitos e sem rótulos.

Sobre o acesso à universidade, a legislação foi modificada recentemente para poder oferecer melhor ingresso aos estudantes. A ascensão dos Programas de Açóes Afirmativas (AA), pautados na política nacional pela Lei n. 12.711/2012, determina que todas as Instituições Federais de Ensino Superior (Ifes) reservem $50 \%$ de suas vagas para estudantes de escolas públicas, observando-se ainda questôes de renda e étnico-racial. Essa lei foi regulamentada pelo Decreto n. 7.824/2012, que definiu as condiçóes gerais de vagas, estabelecendo a sistemática de acompanhamento das reservas de vagas e a regra de transição para as Ifes. Há, também, a Portaria Normativa n. 18/2012, do Ministério da Educação, que estabelece os conceitos básicos para aplicação da lei, prevê as modalidades das reservas de vagas e as fórmulas para cálculo, fixa as condiçóes para concorrer às vagas reservadas e estabelece a sistemática de preenchimento das mesmas. Há ainda universidades que definem uma determinada porcentagem de vagas para alunos com deficiências, porém, isso depende da política interna de cada instituição.

Rosing (2012) afirma que o sistema de cotas póe lado a lado os alunos mais bem preparados para o meio acadêmico com aqueles integrantes de minorias sociais. Para a autora, isso seria equivalente ao ingresso de alunos na condição de analfabetos funcionais e analfabetos culturais, sendo que programas de reforço estariam sendo destinados a esses alunos nas universidades federais com o objetivo de elevar a capacidade de leitura e escrita nos primeiros semestres da graduação.

A preocupação com o alfabetismo funcional tem tomado um espaço importante nas discussóes sobre educação. Segundo definição da Unesco (1998), "uma pessoa funcionalmente alfabeta é requerida para uma atuação eficaz em seu grupo e comunidade, e que lhe permitem, também, continuar usando a leitura, a escrita e o cálculo a serviço do seu próprio desenvolvimento e do desenvolvimento de sua comunidade". A alfabetização funcional possui vários níveis: aqueles que apenas conseguem ler e compreender títulos de textos e frases curtas; e apesar de saber contar, têm dificuldades com a compreensão de números grandes e em fazer as operações aritméticas básicas. Há aqueles que conseguem ler textos curtos, mas não conseguem extrair informaçôes do texto e não conseguem tirar uma conclusão a respeito do mesmo. E ainda, aqueles que detêm pleno domínio da leitura, escrita, dos números e das operações matemáticas, que são minorias (RIBEIRO, 2000, p.22).

Os dados do Indicador de Alfabetismo Funcional (INAF, 2011) indicam que há 38\% de estudantes na educação superior que apresentam nível de alfabetismo básico e rudimentar. Esse grupo de alunos possivelmente apresenta dificuldades com os gêneros acadêmicos secundários, como: resenhas, resumos, trabalhos de conclusão de curso, relatórios etc. 
Segundo os mesmos dados do Inaf (2011), a renda familiar e o nível de alfabetismo estáo intimamente relacionados, uma vez que a proporçáo de analfabetos e daqueles incluídos no nível rudimentar diminui sensivelmente à medida que aumenta a renda familiar (SARAVALI, 2005). Apesar deste e tantos outros indicadores nacionais que investigam a escolaridade, o letramento e as correlaçóes com o ambiente de convívio e a renda familiar, há poucos estudos, tanto sobre alunos com deficiências, como com alunos com transtornos funcionais e que apresentam dificuldades relacionadas especificamente à leitura e à escrita. Ou ainda, não há pesquisas sobre o analfabetismo funcional relacionadas a esse grupo de alunos no ensino superior.

Logo, é preciso que se discuta seriamente essa questão para que se possa falar efetivamente em "inclusão", não apenas dos "deficientes”, mas de todos os alunos que necessitam de apoio quando ingressam na universidade. Assim, precisa-se de uma educação que supra a necessidade de cada aluno sem homogeneizar o ensino. Há de se considerar ainda que o Brasil é um país marcado pela desigualdade; poucos têm acesso à universidade, apesar desta realidade estar se modificando (SIQUEIRA; SANTANA, 2010; PEREIRA, 2008).

Temos atualmente políticas públicas com a finalidade de promover a inclusão de todos os estudantes. O Programa de Extensão Universitária (Proext), por exemplo, tem o objetivo de apoiar as instituiçóes públicas de ensino superior no desenvolvimento de programas ou projetos de extensão que contribuam para a implementação de políticas públicas. Criado em 2003, o Proext abrange a extensão universitária com ênfase na inclusão social (BRASIL, 2008a).

O Plano Nacional de Assistência Estudantil (Pnaes), criado pelo Decreto n. 7.234, de 19 de janeiro de 2010, apoia a permanência de estudantes de baixa renda matriculados em cursos de graduação presencial das Ifes. O objetivo é viabilizar a igualdade de oportunidades entre todos os estudantes e contribuir para a melhoria do desempenho acadêmico a partir de medidas que buscam combater situações de repetência e evasão (BRASIL, 2010a). Nesse caso, vê-se que o plano é aberto de modo que cada universidade possa realizar as açóes que sejam pertinentes.

O Programa de Acessibilidade na Educação Superior (Incluir) propóe ações que garantam o acesso pleno de pessoas com deficiência às Ifes. O Incluir tem como principal objetivo fomentar a criação e a consolidaçâo de núcleos de acessibilidade, os quais respondem pela organização de açóes institucionais que garantam a integração de pessoas com deficiência à vida acadêmica, eliminando barreiras comportamentais, pedagógicas, arquitetônicas e de comunicação (BRASIL, 2005). Desde 2005, esse programa lança editais com a finalidade de apoiar projetos de criação ou reestruturação desses núcleos nas Ifes. São recebidas propostas de universidades do Brasil, mas somente as que atendam às exigências do programa são selecionadas para receber o apoio financeiro do Ministério de Educação e Cultura (MEC).

Souza (2010) analisou os editais e projetos do Incluir: dos 71 projetos aprovados entre os anos de 2005 a 2009, apenas 13 responderam os questionários de pesquisa $(18,30 \%)$ enviados pela autora. Ela fez questóes relacionadas aos aspectos 
positivos e negativos desse programa. Como aspectos positivos, apontados pelos entrevistados: valorizaçáo de oportunidades para compra de equipamentos; envolvimento da comunidade; fortalecimento da política de inclusão; ajuda a preparar as pessoas; fortalecimento no compromisso com a humanização, a diversidade; favorece o apoio didático pedagógico. Como aspectos negativos: o programa Incluir contempla apenas parcialmente as açóes; consegue-se dar 30\% de acessibilidade física, mas ainda falta formação para os professores; as verbas são insuficientes; há necessidade de parcerias para a contratação de professores; há necessidade de uma política real de inclusão; não há interesse em analisar os resultados das propostas realizadas, apenas os resultados financeiros. A autora chegou assim às seguintes conclusóes a partir de sua pesquisa: o programa Incluir ainda consegue atender às universidades porque há poucos alunos com deficiência, contudo, ainda não se contemplam efetivamente as necessidades dos alunos. Embora o programa auxilie as açóes inclusivas, ele não garante totalmente o acesso e nem a permanência dos alunos.

O programa Incluir aparece antes da criação de um Núcleo de Acessibilidade que só se tornou obrigatório nas universidades federais a partir do decreto n. 7.611, de 17 de novembro de 2011. O artigo sétimo discorre sobre a estruturação de núcleos de acessibilidade nas Ifes. De acordo com o mesmo, os núcleos de acessibilidade visam eliminar barreiras físicas, de comunicação e de informação que restringem a participação e o desenvolvimento acadêmico e social de estudantes com deficiência. Sendo assim, o núcleo de acessibilidade auxilia a garantir um direito previsto na portaria n. 3.284, de 7 de novembro de 2003, que assegura aos deficientes físicos e sensoriais condições básicas ao acesso no ensino superior, assim como nas questóes de mobilidade, utilização de equipamentos e instalações das instituiçôes de ensino.

A partir dessas considerações o objetivo deste trabalho é discutir o funcionamento do Programa Institucional de Apoio Pedagógico aos Estudantes (Piape) da Universidade Federal de Santa Catarina (UFSC) a partir de dois contextos: a Coordenadoria de Acessibilidade Educacional (CAE) e o Apoio Pedagógico.

\section{Metodologia}

Essa pesquisa foi realizada na UFSC. A escolha dessa universidade para a pesquisa está relacionada com a participação da mesma no Núcleo de Pesquisa do Projeto em rede "Acessibilidade no Ensino Superior: da análise das políticas públicas educacionais ao desenvolvimento de mídias instrumentais sobre deficiência e inclusão" (Obeduc/Capes). A UFSC é considerada uma universidade relevante, ocupando o $7^{\circ}$ lugar no ranking das melhores universidades brasileiras (FOLHA DE S.PAULO, 2013). A UFSC conta com 11 centros de ensino em 4 cidades: Florianópolis, Araranguá, Curitibanos e Joinville.

A análise do funcionamento da Coordenadoria de Acessibilidade Educacional (CAE) e do Apoio Pedagógico será realizada a partir dos seguintes procedimentos: 
1. Pesquisa documental realizada na internet através da página da UFSC (www.ufsc.br). Utilizou-se o sistema de busca de palavras-chave, lançadas no link tais como: "inclusão", "acessibilidade", "núcleo" e "apoio pedagógico".

2. Descrição do funcionamento da CAE e do Apoio Pedagógico através da análise das páginas da web e de contato e entrevista com os gestores desses programas.

3. Descrição da forma de coleta e do mapeamento de alunos com deficiência matriculados nos cursos de graduação e pós-graduação da UFSC, e dos alunos com transtornos funcionais e/ou dificuldades de aprendizagem. A confirmação dos dados foi realizada através de contato e/ou entrevistas com os profissionais com o objetivo de verificar a veracidade das informaçóes obtidas através do site da UFSC e obtenção mais detalhada do mapeamento dos alunos realizado pelo CAE.

\section{Resultados e discussão}

\section{O Plano Nacional de Assistência Estudantil (Pnaes) no contexto da UFSC}

Primeiramente, é importante ressaltar que tanto a Coordenadoria de Acessibilidade Educacional (CAE) quanto o Apoio Pedagógico são programas que estão relacionados ao Pnaes. Para dar conta das obrigatoriedades desse plano, a UFSC criou o Programa Institucional de Apoio Pedagógico aos Estudantes (Piape).

Com a reformulação do Programa de Ações Afirmativas (PAA), que objetivava somente o apoio a estudantes advindos de cotas, o Piape é uma ação conjunta da Pró-Reitoria de Graduação (Prograd) juntamente com a Pró-Reitoria de Assuntos Estudantis (Prae), constituído com caráter mais universal, abrangendo toda a comunidade acadêmica, ou seja, desde alunos com dificuldades e com necessidades especiais até docentes e coordenadores de curso. As açóes do Piape abrangem açóes voltadas à permanência de estudantes com vulnerabilidade socioeconômica, iniciativas relacionadas à acessibilidade curricular de alunos com deficiências e capacitação continuada de professores (Profor).

Deste modo, dentre outros objetivos, o programa objetiva promover açôes de apoio que favoreçam a permanência e a qualidade dos processos de formação dos estudantes nos cursos de graduação da UFSC, proporcionando-lhes condições pedagógicas que atendam as suas necessidades de aprendizagem. Além do trabalho de monitoria oferecido em grupo ou individualmente, tem como objetivo desenvolver açóes de apoio pedagógico para estudantes com necessidades especiais e/ou outras necessidades específicas, para que possam desenvolver suas atividades acadêmicas com qualidade, além de reduzir os índices de reprovaçáo e evasão nos diversos cursos de graduação, tendo como eixo principal o acom- 
panhamento pedagógico de discentes e docentes. Além disso, estão previstas açôes como: desenvolvimento de material didático específico para as atividades de apoio pedagógico; desenvolvimento de atividades de acolhimento aos novos estudantes ingressantes em cada semestre letivo; desenvolvimento de ambientes virtuais de aprendizagem, com a disponibilização de material didático e tutoriais para acompanhamento dos conteúdos abordados no apoio, realizado de forma individual ou grupal.

Ademais, o Piape prevê açóes de oficinas com temática variada, realizadas em cada semestre, com o objetivo de aproximar o aluno de atividades culturais e apropriação de tecnologias que auxiliem e organizem os estudos.

Em 2013, a Coordenadoria de Avaliação e Apoio Pedagógico, juntamente com a Prograd e a Prae, divulgaram por meio virtual uma cartilha sobre Diretrizes do Programa Institucional de Apoio Pedagógico aos Estudantes de Graduação, que consiste em explicar o Piape para toda a comunidade acadêmica. O programa tem como objetivo proporcionar apoio pedagógico aos processos de aprendizagem dos estudantes de graduação.

Assim, a cartilha afirma que devido ao "alargamento do acesso à Universidade para estudantes de origem social diversa daqueles que historicamente compuseram seu público e a caracterizaram como instituição de formação elitizada, [este] traz novos desafios a professores e dirigentes" (UFSC, 2013).

Outro dado que essa cartilha retrata é o alto índice de reprovação e abandono nos cursos de graduação, que estão ocorrendo concomitantemente à abertura de novas vagas, deixando subentendido que tal fato pode ser devido aos novos alunos provenientes de escolas públicas e/ou de baixa renda. A criação destes programas foi motivada pelas crescentes taxas de reprovação e abandono, isto após a ampliação de vagas através de programas como o Reestruturação e Expansão das Universidades Federais (Reuni). Ainda, afirma: "fenômeno este que exige atenção e análise qualificada, sob o risco de se banalizar com diagnósticos superficiais o que é bastante complexo".

Vejamos abaixo especificamente dois Programas: Coordenadoria de Acessibilidade Educacional e o Apoio Pedagógico.

\section{Coordenadoria de Acessibilidade Educacional (CAE)}

O CAE é um programa novo na UFSC. Anteriormente, esse órgão era denominado de Núcleo de Acessibilidade, mas a partir de outubro de 2012 passou a se chamar Coordenadoria de Acessibilidade Educacional, vinculado à Prograd. A Coordenadoria atua com a graduação e a pós-graduação e possui uma equipe multiprofissional composta por duas pedagogas, uma fonoaudióloga, uma psicóloga educacional e sete bolsistas. Esse grupo está diretamente envolvido com 
trabalhos voltados à universidade, ao Colégio de Aplicação da UFSC e ao Núcleo de Desenvolvimento Infantil (NDI).

São quatro as açóes principais realizadas pela CAE:

i) proporcionar açóes de acessibilidade educacional junto à comunidade universitária, propondo cursos e eventos para formação continuada dos servidores e técnicos administrativos e docentes;

ii) articular intersetorialmente a proposição e implementação de políticas públicas de inclusão na UFSC;

iii) oferecer suporte aos cursos de graduação e programas de pós-graduação e demais atividades acadêmicas da UFSC, garantindo um espaço de acolhimento e discussão acerca das práticas pedagógicas cotidianas relativas à inclusão dos estudantes com deficiência;

iv) orientar os estudantes com deficiência e a comunidade acadêmica acerca das açốes relacionadas à acessibilidade na instituição.

Vemos que só a partir do decreto de novembro de 2011 as universidades começaram a movimentar-se em busca da criação de um órgão que pudesse oferecer e favorecer a inclusão na instituiçãoo. Ou seja, as açôes ainda são muito recentes e, pode-se dizer, ainda estão em fase de implantação. Há ainda o desconhecimento de muitos alunos sobre o trabalho realizado pela CAE e mesmo a divulgação, no site, ainda ocorre de forma fragmentada.

Ao realizarmos uma busca sobre a CAE, observamos que náo foi de fácil localização. As informaçóes estavam todas fragmentadas. Para localizá-las foi necessário clicar no campo de pesquisa e digitar o buscador "acessibilidade". Outro modo de encontrar o tema foi no item de "notícias", que fica disponível na página inicial do site da UFSC, e ler todas as páginas até encontrar a informação referente à CAE. Considerando que há notícias antigas, muitas páginas precisam ser avançadas para obtenção da informação.

Pode-se dizer que o que há sobre a Coordenadoria refere-se às notícias sobre a sua criação, o público atendido, informações sobre a acessibilidade na biblioteca e seminários. Durante o período de um ano, foram encontradas nove notícias referentes à CAE que permanecem até o momento nos sites. ${ }^{6}$

Sobre o público-alvo atendido, no primeiro semestre de 2013, foi realizado pela CAE uma coleta de dados através do sistema de Controle Acadêmico da Graduação (CAGR), do sistema para a pós-graduação (CAGP) e por confirmação via e-mail para os alunos. O objetivo era quantificar e caracterizar o público-alvo da

6 Cf., por exemplo, a notícia "UFSC cria Núcleo de Acessibilidade", sobre público-alvo. Disponível em: http://artes.paginas.ufsc.br/2013/03/04/ufsc-cria-nucleo-deacessibilidade/. Acesso em: 30 out. 2014. 
educação especial. Obteve-se o número de 86 alunos de graduação com deficiência e/ou transtornos globais do desenvolvimento. Já na pós-graduação, há 10 alunos.

Gráfico 1. Distribuição do número de alunos que fazem parte do público-alvo da educaçáo especial na graduação

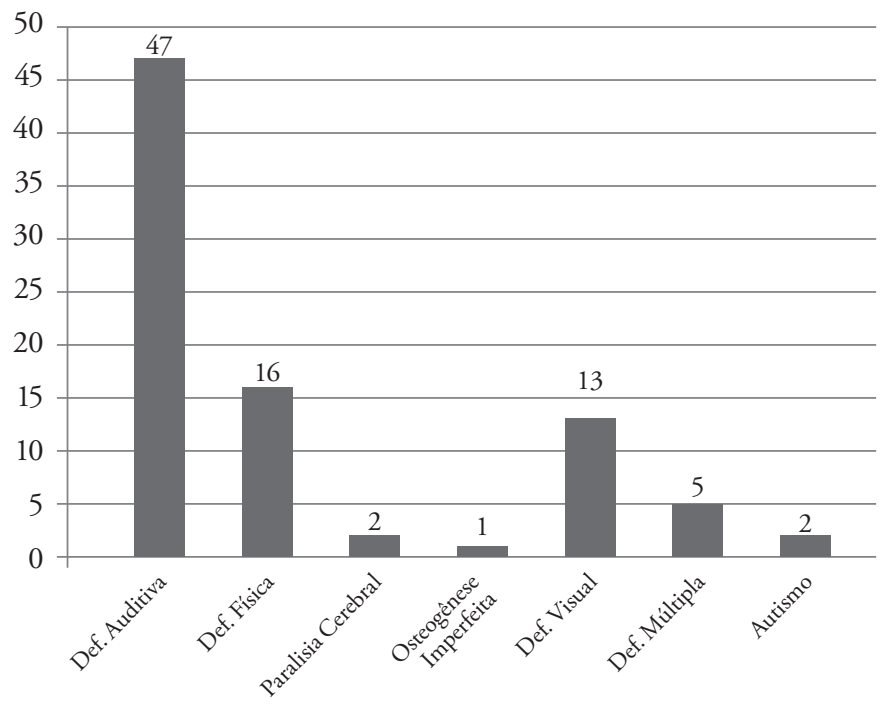

Fonte: Dados da pesquisa.

Gráfico 2. Distribuição do número de alunos da pós-graduação, de acordo com suas deficiências

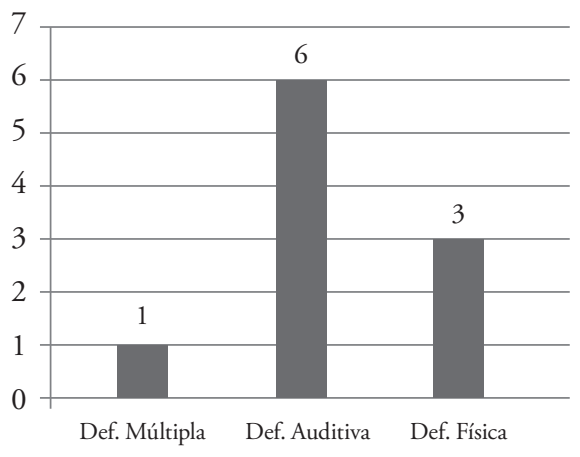

Fonte: Dados da pesquisa.

Através desses dados, percebe-se que grande parte dos alunos com deficiência da graduação possui deficiência auditiva. Dos 81 alunos com deficiência, que corresponde à $0,17 \%$ do número total de alunos matriculados na graduação na 
UFSC, 58,02\% são alunos com deficiência auditiva, 19,75\% são alunos com deficiência física, 16,05\% são alunos com deficiência visual e 6,18\% são alunos com deficiências múltiplas. Não houve matrícula de alunos com deficiências intelectuais naquele ano. Há ainda 5,82\% de alunos público-alvo da educação especial que apresentam outros diagnósticos como autismo, paralisia cerebral e osteogênese imperfeita.

O Censo de 2013 do Inep aponta que em um total de 29.034 alunos matriculados com alguma deficiência, observa-se com deficiência auditiva 29,3\%, deficiência física $27 \%$, deficiência visual $37,6 \%$, deficiência múltipla 1,9\%. São considerados ainda, matriculados no ensino superior, $4,2 \%$ de alunos público-alvo da educação especial categorizados entre autistas, com transtorno desintegrativo da infância, síndrome de Rett ou síndrome de Asperger. (BRASIL, 2014b).

Diferentemente dos percentuais encontrados nas outras universidades e instituiçóes de ensino superior do país, o número de alunos com deficiência auditiva supera outras necessidades específicas. Entretanto, deve ser considerada a oferta do curso de Letras-Libras pela UFSC destinado a atender a essa demanda específica, já que dos 47 deficientes auditivos/surdos na universidade, 30 são do curso de Letras-Libras (64\%).

Acrescente-se também que pode haver mais alunos com deficiência pois a CAE só tem acesso aos alunos que se "autodeclaram" com deficiência e/ou que buscam ajuda. Por exemplo, no curso de Letras-Libras da UFSC, embora tenha sido contabilizado os dados, os surdos desse curso não procuram o apoio da CAE, pois não consideram necessário, já que esse curso possui metodologia específica para os surdos. A grande maioria dos surdos dessa universidade estão no curso de Letras-Libras.

Ainda há relativa dificuldade na realização do mapeamento dos alunos pela falta de informação sobre o quesito da deficiência presente no "cadastro do aluno", não havendo um local em que essa informação possa ser inserida ou atualizada. Ou seja, a questáo do mapeamento dos estudantes ainda precisa ser modificada para que se possa ter uma quantidade real do quadro.

Com relação à pós-graduação, não foi encontrado dados referentes ao Censo de 2013. Na UFSC, temos $0,15 \%$ de alunos com deficiência em relação ao total de alunos matriculados na pós-graduação. Destes, $10 \%$ são alunos com deficiência múltipla, $60 \%$ são alunos com deficiência auditiva e 30\% são alunos com deficiência física. A maioria também é de alunos com deficiência auditiva. Uma das justificativas para essa preponderância pode ser o curso de Letras-Libras, que envolve um grande número de alunos surdos que dáo continuidade aos seus estudos na pós-graduação em Linguística ou em Tradução, já que a UFSC é considerada um centro de referência nos estudos sobre Língua de Sinais (QUADROS; KARNOPP, 2004). 


\section{Apoio Pedagógico}

O apoio aos estudantes no ensino superior é proposto de forma particular para cada instituição, que desenvolve a seu modo um plano de metas e de programas voltados a esse novo público. Esses programas são responsáveis pelo apoio aos acadêmicos que não possuem deficiências, mas que se encontram na universidade e têm dificuldades de diversas ordens. Nesse caso específico, vamos aprofundar o apoio relacionado às questôes de aprendizagem.

As informaçốes do site da UFSC relacionadas ao apoio estudantil referem-se a descrições sobre os programas oferecidos e as formas de contato. Um folder interativo traz as diretrizes do Apoio Pedagógico Estudantil aos graduandos (Piape), onde estão inseridas as ações desde a CAE até a formação continuada de docentes. Não há especificaçôes sobre o público-alvo do Apoio Pedagógico. Só se sabe que não podem ser acadêmicos com deficiências.

A pesquisa no site foi realizada no ano de 2014. Sendo assim, foram encontradas as seguintes informações: ${ }^{7}$

i) o Apoio Pedagógico é voltado aos conteúdos disciplinares, sendo que as disciplinas contempladas são as que apresentam maiores índices de reprovação nos primeiros semestres;

ii) oficinas (já realizadas, em andamento ou que serão ministradas no decorrer do período letivo);

iii) editais para tutores de grupos de aprendizagem e orientadores pedagógicos e educacionais;

iv) equipe que integra o Apoio Pedagógico.

A equipe do Apoio Pedagógico era formada, no ano de 2014, por: um psicólogo, uma pedagoga, uma assistente administrativa e a coordenadora de avaliação do apoio pedagógico (que é uma técnica de assuntos educacionais com mestrado em História Cultural). Não há fonoaudiólogo na equipe.

Em 2013, a CAE passou para o Apoio Pedagógico todos os alunos com transtornos funcionais, que antes eram atendidos por ela: alunos com transtorno de déficit de atenção (TDA) e/ou com hiperatividade (TDAH), distúrbio do processamento auditivo central (DPAC), dislexia, transtorno obsessivo compulsivo (TOC) e síndrome de Meares-Irlen.

Com relação aos encaminhamentos feitos a esse órgão institucional, geralmente o aluno com transtorno ou dificuldade de leitura e escrita chega até o Apoio Pedagógico encaminhado por um professor ou coordenador durante a graduação, ou procura isoladamente o programa nos primeiros semestres letivos,

7 Página na web do Apoio Pedagógico: http://apoiopedagogico.prograd.ufsc.br/. Acesso em: 30 out. 2014. 
seja para dar ênfase em suas necessidades educacionais, seja para conscientizar a equipe pedagógica de seu curso ou mesmo para solicitar propriamente apoio em disciplinas ou na graduação em geral. $\mathrm{O}$ atendimento a esses alunos será realizado pela coordenadora do Apoio Pedagógico que, juntamente com a equipe e a coordenação do curso do qual veio o aluno, discutirão as medidas necessárias para garantir que as dificuldades do acadêmico sejam sanadas. $\mathrm{O}$ atendimento feito especificamente pelo Apoio Pedagógico envolve aulas em grupo ou individuais, com auxílio de tutores e materiais pedagógicos complementares, porém o aluno não terá adaptação de provas e bolsistas individuais em sala de aula, como ocorre com os alunos da CAE. A proposta é amparar e acompanhar esses acadêmicos que adentram no ensino superior. Esse apoio não está relacionado a um atendimento clínico, embora possa solicitar encaminhamentos. O objetivo é o auxílio e formulação de estratégias para adequar, melhorar e garantir a permanência no ambiente educacional. Embora cumpra com seu papel de apoio aos alunos com dificuldades disciplinares em geral, o grupo de alunos com transtornos ainda é um grupo bastante heterogêneo e que não possui uma identificação precisa. Esse é um público que ainda está oculto.

Em 2013, a CAE fez um mapeamento que envolveu alunos com transtornos funcionais que buscaram ajuda e deu a eles o mesmo apoio que dá aos alunos com deficiência. Sendo assim, temos 17 alunos de acordo com o mapeamento realizado em 2013:

Gráfico 3. Distribuição do número de alunos de acordo com os tipos de transtornos funcionais

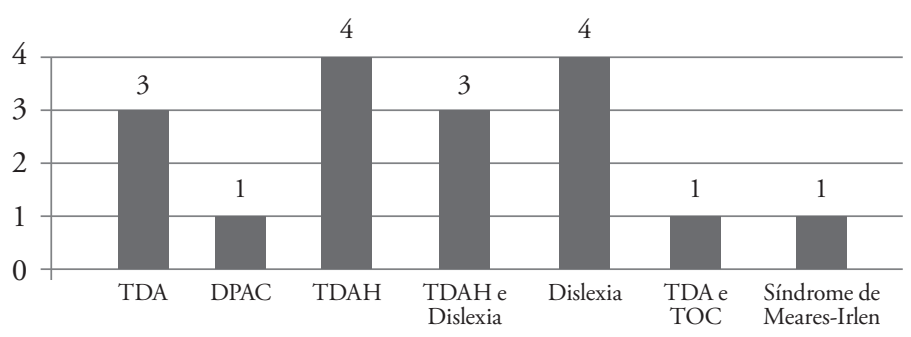

Fonte: Elaborado pelos autores.

O mapeamento desses alunos é ainda utópico visto que não há uma política institucional que consiga identificar tais alunos. Ou seja, há muitos alunos com diagnósticos de transtornos funcionais (transtornos de déficit de atenção e hiperatividade, dislexia, transtornos de leitura e escrita, dentre outros) que não se identificaram. Há ainda outros alunos que recebem diagnósticos e/ou rótulos de transtornos funcionais, mas, na verdade, o que possuem é uma história de má alfabetização associada à falta de hábitos de leitura e de escrita. Há ainda tantos outros que são 
analfabetos funcionais e que precisam também de apoio, pois têm dificuldades com relação à sua permanência na universidade (SANTANA et al., 2014).

Esses alunos com dificuldades de leitura e escrita também buscam, em grande quantidade, a clínica de fonoaudiologia da UFSC, através dos projetos de extensão, mas nem sempre entram no mapeamento do Apoio Pedagógico ou mesmo querem buscar esse apoio (SOUSA, 2014). Não há, assim, como mapear esses alunos.

O que vemos nessa discussão é que, se a nova realidade do ensino superior apresenta questóes como o sucesso e o fracasso escolar de indivíduos de classes economicamente menos favorecidas, a universidade ainda não consegue dar efetivamente apoio a esses alunos por vários motivos: muitos não se identificam por não saberem que há um local de apoio específico para eles, ou por ter receio de serem discriminados pelos professores e colegas; muitos sabem que têm dificuldades, entretanto, não sabem quais seriam elas nem que pessoas poderiam procurar para resolver tais dificuldades (SANTANA, 2014). Deste modo, é necessário uma grande mudança na preparação de profissionais, professores e ainda de açóes para esse grupo de alunos que ficam marginalizados em torno de preconceitos e de rótulos de "maus alunos". Esse rótulo é legitimado pelo próprio aluno quando não busca apoio para não ser diferente dos demais. Assim, é necessário discutir essas questóes a partir de um universo maior do que somente analisar a dificuldade do aluno.

O que se observa é que há a necessidade de profissionais capacitados para atender a essa nova demanda no ensino superior. Segundo Santana e Stolsky (2014), a ação da fonoaudiologia, nesse contexto, é também importante, embora a fonoaudiologia educacional, que trabalha com promoção de letramento, formação de professores e encaminhamentos, ainda seja praticamente desconhecida no contexto da universidade. As autoras ainda comentam ser necessário que os professores recebam orientação sobre como lidar com a heterogeneidade na sala de aula e, além disso, há necessidade de açóes voltadas para os alunos com a finalidade de solucionar e/ou diminuir suas dificuldades.

\section{Conclusão}

As mudanças no cenário educacional brasileiro são recentes, a homogeneidade do ensino modificou-se a partir de políticas públicas que possibilitaram o ingresso de indivíduos que possuem deficiências, diferentes níveis de escolaridade, práticas de letramento diferenciadas e trajetórias distintas, criando expectativas tanto do aluno quanto da instituição. Observa-se nas salas de aula das instituições e ensino superior turmas heterogêneas. Mas ingressar no ensino superior brasileiro não significa a garantia da conclusão do curso tão almejado, pois para isso é necessário que a universidade possa oferecer condiçôes de permanência.

No caso das políticas públicas que discutimos, vemos que já há um grande avanço se considerarmos que o Pnaes é de 2010, a criação do Núcleo de Acessi- 
bilidade é de 2011 e as Ações Afirmativas de 2012. Ou seja, nos quatro últimos anos houve uma modificaçáo considerável nas políticas educacionais do ensino superior. Desta forma, por ser uma realidade muito recente, entende-se que ainda estamos em processo de implantação dessas políticas públicas. Há ainda muito por avançar. Fica evidente que são necessárias estratégias eficazes para identificar não apenas os alunos com deficiência mas também os que possuem transtornos funcionais, para auxiliá-los, assegurando a inclusão.

Vemos, a partir deste trabalho, que o programa institucional de apoio aos estudantes (UFSC) está em processo de implantação para efetivar o Plano Nacional de Assistência Estudantil. Esse plano é aberto o suficiente para permitir que cada universidade elabore seus programas a partir de seu contexto social e das necessidades de cada local.

No contexto da UFSC, esse trabalho constatou que ainda há dificuldades que envolvem o mapeamento dos alunos, o acesso às informaçóes dos programas e ainda o entendimento do próprio aluno no que se refere às políticas educacionais atuais, já que muitos não buscam apoio. Sabe-se que essas mudanças exigem revisão de conceitos e paradigmas, assim como de direitos e deveres. Desse modo, se de um lado a universidade deve efetivar a inclusão de todos, do outro, o aluno também deve estar informado sobre as açóes que a universidade oferece para apoiar a sua permanência e participar desses programas, para que a educação possa ser realmente para todos. ${ }^{8}$

\section{Referências}

BRASIL. Constituição da República Federativa do Brasil, 1988. Brasília: Senado Federal, Centro Gráfico, 1988.

BRASIL. Leis e Decretos. Lei n. 9.394, de 20 de dezembro de 1996. Estabelece as Diretrizes e Bases da Educação Nacional. Brasília, DOU, 23/12/1996. Disponível em: http://www. planalto.gov.br/ccivil_03/leis/19394.htm. Acesso em: 8 out. 2014.

BRASIL. Decreto n. 5.296, de 2 de dezembro de 2004. Regulamenta as Leis n. 10.048, de 8 de novembro de 2000, que dá prioridade de atendimento às pessoas que especifica, e n. 10.098, de 19 de dezembro de 2000, que estabelece normas gerais e critérios básicos para a promoção da acessibilidade das pessoas portadoras de deficiência ou com mobilidade reduzida, e dá outras providências. Presidência da República. Casa Civil. Subchefia para Assuntos Jurídicos. Brasília, dez. 2004. Disponível em: http://www.planalto.gov.br/ccivil_03/_ ato2004-2006/2004/decreto/d5296.htm. Acesso em: 9 maio 2013.

BRASIL. Programa Incluir. 2005. Disponível em: http://portal.mec.gov.br/index.php?Itemid=495\&id=12257\&option=com_content\&view=article. Acesso em: 20 set. 2014.

8 Agradecemos ao CNPq e à Capes pelo apoio que recebemos para esta pesquisa. 
BRASIL. Decreto n. 6495, de 30 de junho de 2008. Institui o Programa de Extensão Universitária (Proext). Brasília, 2008a. Disponível em: http://www.planalto.gov.br/ccivil_03/_ Ato2007-2010/2008/Decreto/D6495.htm. Acesso em: 10 jul. 2014.

BRASIL. Política Nacional de Educação Especial na Perspectiva da Educação Inclusiva. Brasília: MEC, Secretaria de Educaçáo Especial, 2008b. Disponível em: http://peei.mec.gov.br/arquivos/ politica_nacional_educacao_especial.pdf. Acesso em: 20 set. 2014.

BRASIL. Decreto n. 7.234, de 19 de janeiro de 2010. Dispóe sobre o Programa Nacional de Assistência Estudantil (Pnaes). Brasília, 19 jan. 2010a. Disponível em: http://www.planalto. gov.br/ccivil_03/_Ato2007-2010/2010/Decreto/D7234.htm. Acesso em: 10 jun. 2014.

BRASIL. Ministério da Educação. INEP. Censo da Educaçâo Superior de 2009. Resumo técnico. Brasília, Inep, 2010b. Disponível em: http://download.inep.gov.br/download/superior/ censo/2009/resumo_tecnico2009.pdf. Acesso em: 9 maio 2013.

BRASIL. Decreto n. 7.611, de 17 de novembro de 2011. Dispóe sobre a educação especial, o atendimento educacional especializado e dá outras providências. Brasília, 17 nov. 2011. Disponível em: http:/www.planalto.gov.br/ccivil_03/_Ato2011-2014/2011/Decreto/D7611. htm\#art11. Acesso em: 10 jul.2014.

BRASIL. Lei n. 12.711, de 29 de janeiro de 2012. Dispóe sobre o ingresso nas universidades federais e nas instituiçôes federais de ensino técnico de nível médio e dá outras providências. Brasília, 10 de junho de 2012. Disponível em: http://www.planalto.gov.br/ccivil_03/_ ato2011-2014/2012/lei/112711.htm. Acesso em: 20 set. 2014.

BRASIL. Ministério da Educação. INEP. Censo da Educação Superior, 2012. Resumo técnico. Brasília: Inep, 2014a. Disponível em: http://download.inep.gov.br/download/superior/ censo/2012/resumo_tecnico_censo_educacao_superior_2012.pdf. Acesso em: 13 nov. 2014.

BRASIL. Ministério da Educação. INEP. Censo da Educação Superior, 2013. Brasília: Inep, 2014b. Disponível em: http://download.inep.gov.br/educacao_superior/censo_superior/ apresentacao/2014/coletiva_censo_superior_2013.pdf. Acesso em: 15 jun. 2015.

FELICETTI, V. L.; MOROSINI, M. C. Equidade e iniquidade no ensino superior: uma reflexão. Ensaio: aval. pol. públ. educ., Rio de Janeiro, v.17, n.62, mar. 2009. Disponível em: http://www.scielo.br/scielo.php?script=sci_arttext\&pid=S0104-40362009000100002\&lng= en\&nrm=iso. Acesso em: 15 set. 2014.

FOLHA DE S.PAULO. Ranking Universitário Folha, 2013. Disponível em: http://ruf.folha. uol.com.br/2013/rankinguniversitariofolha/. Acesso em: 30 dez. 2013.

INAF. Indicador de Alfabetismo Funcional 2011: principais resultados. Disponível em: http:// www.ipm.org.br/download/informe_resultados_inaf2011_versao\%20final_12072012b.pdf. Acesso em: 30 jun. 2014.

MASINI, E. F. S.; BAZON, F. V. M. A inclusão de estudantes com deficiência, no ensino superior. Reunião anual da Anped, 28, 2005, Caxambu. Anais da 28a reunião anual. Caxambu: Anped, 2005. Disponível em: http://www.anped.org.br/reunioes/28/inicio.htm. Acesso em: 22 ago. 2013.

ONU. Organização das Naçôes Unidas. Convençâo sobre os direitos das pessoas com deficiência. Protocolo aprovado pela Assembleia Geral das Nações Unidas, 6 dez. 2006. Disponível em: http://www.assinoinclusao.org.br/Downloads/Convencao.pdf. Acesso em: 14 jun. 2015.

PEREIRA, M. M. Ações afirmativas e inclusão de alunos com deficiência no Ensino Superior. Ponto de Vista, Florianópolis, n.10, p.19-38, 2008. Disponível em https://periodicos.ufsc.br/ index.php/pontodevista/article/view/20567/18780. Acesso em: 1 nov. 2014.

QUADROS, R. M; KARNOPP, L. Lingua de sinais brasileira: estudos linguísticos. Porto Alegre: Artmed, 2004. 222p. 
RIBEIRO, V. M. Dimensões atitudinais do alfabetismo. Quaestio: Revista de Estudos em Educação, n.2, v.2, p.21-36, 2000. Disponível em: http://periodicos.uniso.br/ojs/index. php?journal =quaestio\&page $=$ article\&op=view\&path $\% 5 B \% 5 \mathrm{D}=1434 \&$ path $\% 5 \mathrm{~B} \% 5 \mathrm{D}=1410$. Acesso em: 10 ago. 2013.

ROSING, T. M. K. Diferentes espaços de leitura e escrita no ensino superior: a situação brasileira. Nuances: Estudos sobre Educação, ano XVIII, v.21, n.22, 2012, p.61-75. Disponível em: http://revista.fct.unesp.br/index.php/index/search/results. Acesso em: 30 jul. 2014.

SANTANA, A. P. O. et al. O apoio pedagógico na educação superior: promovendo a permanência. Apresentação de pôster no 22 ${ }^{\circ}$ Congresso Brasileiro de Fonoaudiologia. Joinville, 2014.

SANTANA, A. P.; STOLSKY, M. Atuação fonoaudiológica na educação superior: do ingresso à permanência. In: MARCHESAN, I. Q.; DILVA, H. J.; TOMÉ, M. C. (Orgs.). Tratado das especialidades em fonoaudiologia. São Paulo: Roca, 2014. p.488-496.

SANTANA, A. P. Letramento, cultura escrita e educação superior: a universidade é para todos? 62o GEL (Grupo de Estudos Linguísticos), 2014, Anais do 62o GEL (Grupo de Estudos Linguísticos). Campinas: Unicamp, 2014. Disponível em http://gel.org.br/detalheResumo2014. php?id=2149. Acesso em: 15 jun. 2015.

SARAVALI, E. G. Inclusão x exclusão: contribuiçóes das pesquisas em sociometria para o debate da reforma universitária no Brasil. Revista Umbral 2000, por una educación para un mundo nuevo, Chile, v.17, n.1, p.1-15, 2005.

SCARDUA, V. M. A inclusão e o ensino regular. FACEVV, Vila Velha, v.1, p.85-90, 2008.

SIQUEIRA, I. M.; SANTANA, C. S. Propostas de acessibilidade para a inclusão de pessoas com deficiências no ensino superior. Rev. Bras. Educ. Espec., Marília, v.16, n.1, abr. 2010. Disponível em: http://www.scielo.br/scielo.php?script=sci_arttext\&pi$\mathrm{d}=$ S1413-65382010000100010\&lng=en\&nrm=iso. Acesso em: 1 nov. 2014.

SOUSA, A. S. B. Os alunos com queixa de dificuldades de leitura e escrita na educação superior. 2014. Trabalho de Conclusão de Curso. 57f. Graduação em Fonoaudiologia. Universidade Federal de Santa Catarina, Florianópolis, 2014.

SOUZA, B. C. S. Programa Incluir (2005-2009): uma iniciativa governamental de educação especial para a educação superior no Brasil. 2010. 179p. Dissertação (Mestrado em Educação). Universidade Federal de Santa Catarina. Florianópolis, 2010.

UNESCO. Declaração mundial sobre educação para todos: satisfação das necessidades básicas de aprendizagem. 1998. Disponível em: http://unesdoc.unesco.org/images/ 0008/000862/086291por.pdf. Acesso em: 19 jun. 2015.

UNIVERSIDADE FEDERAL DE SANTA CATARINA (UFSC). Coordenadoria de Avaliação e Apoio Pedagógico. Disponível em: http://apoiopedagogico.prograd.ufsc.br/. Acesso em: 1 nov. 2014.

UNIVERSIDADE FEDERAL DE SANTA CATARINA (UFSC). Diretrizes do Programa Institucional de Apoio Pedagógico aos Estudantes (Piape). 2013. Disponível em: http://apoiopedagogico. prograd.ufsc.br/apoio-pedagogico/. Acesso em: 1 nov. 2014.

UNIVERSIDADE FEDERAL DE SANTA CATARINA (UFSC). Programa incluir tenta viabilizar acessibilidade universal na UFSC. 2008. Disponível em: http://noticias.ufsc.br/2008/06/ programa-incluir-tenta-viabilizar-acessibilidade-universal-na-ufsc/l. Acesso em: 10 maio 2014.

VARGAS, G. M. S. A inclusão no ensino superior: a experiência da disciplina "Prática Pedagógica - Prática de Ensino" de uma turma de alunos cegos e com baixa visão. Ponto de Vista, Florianópolis, n.8, p.131-138, mar. 2006. Disponível em: https://periodicos.ufsc.br/index.php/ pontodevista/article/viewFile/1124/1459. Acesso em: 1 nov. 2014. 


\section{Resumo}

\section{Acessibilidade e permanência: um estudo do programa institucional de apoio aos estudantes da Universidade Federal de Santa Catarina}

Com a democratização do ensino superior há necessidade de políticas educacionais que deem conta da diversidade de alunos advindos de ambientes sociais diversos e de estudantes que são o público-alvo da educação especial. O Plano Nacional de Assistência Estudantil, por exemplo, criado em 2010, objetiva viabilizar a igualdade de oportunidades entre todos os estudantes. O objetivo deste trabalho é analisar o Programa Institucional de Apoio aos Estudantes da Universidade Federal de Santa Catarina com relação a dois programas: Coordenadoria de Acessibilidade Educacional e Apoio Pedagógico. A metodologia envolve: pesquisa documental, descrição do funcionamento dos programas e mapeamento de alunos com deficiência e dos alunos com transtornos funcionais e/ou dificuldades de aprendizagem. Os resultados demonstram que, embora o número de estudantes seja significativo, na universidade, esse tipo de apoio é muito recente e está em processo de implantação. Há dificuldades que envolvem o mapeamento dos alunos, o acesso às informaçóes dos programas e, ainda, o entendimento do próprio aluno com relação a esses programas.

Palavras-chave: Apoio Pedagógico. Acessibilidade. Inclusão. Ensino Superior.

\section{Abstract \\ Accessibility and Stay in the University: A Study on the Institutional Program of Educational Support to Students}

The democratization of higher education promotes a need for educational policies that take account of the diversity of students originated from distinct social environments and students from special education. The National Plan for Student Assistance, for example, established in 2010 aims at providing equal opportunities for all students. The objective of this work is to analyze the Institutional Program of Support to the Students of the Universidade Federal of Santa Catarina regarding two programs: Department of Educational Accessibility and Pedagogical Support. The methodology involves documentary research, description of the operation of the programs and mapping of students with disabilities and students with functional disorders and/or learning difficulties. The results show that, although the number of students is significant, at the university, this type of support is very recent and is in the process of deployment. There are difficulties that involve the mapping of students, accessing information on the programs and the understanding of the student with respect to these programs.

Keywords: Educational Support. Accessibility. Inclusion. Higher Education. 